\title{
Price and Delivery Time Analyzing in Competition between an Electronic and a Traditional Supply Chain
}

\author{
M. Narenji, Mohammad Fathian, Ebrahim Teimoury, and Seyed Gholamreze Jalali Naini \\ School of Industrial Engineering, Iran University of Science and Technology, Narmak, Tehran 16846113114, Iran \\ Correspondence should be addressed to M. Narenji; mnarenji@iust.ac.ir
}

Received 3 April 2013; Accepted 23 September 2013

Academic Editor: Dongdong Ge

Copyright ( 2013 M. Narenji et al. This is an open access article distributed under the Creative Commons Attribution License, which permits unrestricted use, distribution, and reproduction in any medium, provided the original work is properly cited.

\begin{abstract}
In this paper, the competition between two supply chains and their corresponding elements is modeled following the evolutionary games approach. Each of the supply chains consists of a supplier and a manufacturer. Customers are of one type and are sensitive to price and delivery time and receive identical services from the two supply chains. One of the chains acts traditionally (TSC) in a monopoly market until the other chain enters the market acting electronically (ESC) and changes the market to a duopoly. This competition continues as evolutionary game until equilibrium is reached in the market. Mathematical models for analyzing internal and external competition issues are developed under four different scenarios: (i) both chains choose intercorporate strategy for their elements; (ii) the first chain chooses intercorporate strategy while the second one chooses intercompetition strategy for their elements; (iii) the first chain chooses intercompetition strategy and the second one chooses intercorporate strategy for their elements; (iv) both chains choose intercompetition strategy for their elements. The best policies for TSC and ESC are found assuming identical conditions and furthermore in steady state when equilibrium is reached in the market, the best price and delivery time policy of chains is illustrated by numerical example.
\end{abstract}

\section{Introduction}

Competition between supply chains to achieve greater market share in competitive environment is a common theme in the literature. Several strategies have been discussed to integrate the business process and activities of internal elements in a supply chain to improve system-wide performance of the chain in terms of price, delivery time, and customer service. Using the internet and applying electronic processes is one of those strategies to bring a core competency. Mendelson and Whang [1] proposed an $M / M / 1$ queuing model with multiple user classes where price plays dual role: determination of priorities and allocation of service capacity. They presented an incentive-compatible pricing mechanism in the sense that both the execution priorities and arrival rates maximize the expected net value of the system which is determined on a decentralized basis. Dewan and Mendelson [2] investigated optimal allocation decisions for a service facility, taking into account both the capacity cost and users' delay cost, and modeled the facility as a queuing system in which users have general nonlinear delaycost functions assuming that service requests are homogeneous. Stidham [3] studied a service facility with a restriction in the arrival rate in the long-run pricing and capacity design problem. Lee and Kim [4] formulated two models for a single product with stable demand to determine price, demand, lot size, and marketing expenditure: the full integration model which determines all decisions involved simultaneously and the partial integration model that separates the lot sizing decision from the others. Li and Lee [5] studied pricing and deliverytime performance in a competitive environment. Lederer and $\mathrm{Li}$ [6] used a competitive model to find the effect of responsiveness on prices, supply chain's profits, and customer demands in two cases: in the first case supply chains are different in mean processing time, processing time variety, and cost where customers are homogeneous. In the second case supply chains are different in mean processing time and cost where customers are differentiated by demand function and delay sensitivity. Palaka et al. [7] developed a model for delay-sensitive customers, and the firm which 
pays lateness penalties whenever the actual lead-time exceeds the quoted lead-time. They also investigated the implications of considering the firm's congestion costs as well as users' delay costs for the capacity utilization, optimal lead-time setting, and pricing decisions of a profit maximizing firm. So and Song [8] developed an optimization model to determine the joint optimal selection of pricing, delivery time guarantee, and capacity expansion and studied the interrelations between them. Tsay and Agrawal [9] proposed the case of two competing retailers who receive a product from same supplier and then sell products to an external market. Their research provided understanding about the behavioral signatures of decentralized distribution channels. So [10] developed a game model to examine the effects of using quoted delivery time on competition. They assumed that demands are sensitive to price and delivery time, and objective function was maximizing the operation profit. They developed a model for each supply chain separately and then expanded each of the models to encompass the conditions in competitive environment. Boyaci and Ray [11] studied a supply chain with two products different in prices and delivery times. They developed an integrated model to generate some scenarios to decide about constrained capacity for none, one, or both of the products. Ray and Jewkes [12] focused on customer leadtime management when both demand and price are leadtime-sensitive. Afèche and Mendelson [13] designed a model to select alternative price-service for a supply chain serving in a monopolistic market. They added penalty cost structure for delays relevant to type of service. Dai et al. [14] introduced the pricing strategies of multiple competitive firms which provide the same service for a common pool of customers where demand at each firm is a linear function. Leng and Parlar [15] provided an excellent review on game theoretical applications in supply chain management. Pekgun et al. [16] analyzed two supply chains competing based on price and delivery time in a common market with common services. They examined the impact of centralization of decisions comparing some scenarios in which none, one, or both of supply chains are decentralized. Boyaci and Ray [17] developed a model to consider the effect of capacity costs to form the optimal differentiation strategy in terms of prices, delivery times, and delivery reliabilities to maximize the profit of firm which sells two products in a capacitated market. Allon and Federgruen [18] studied a market for an industry of competing service facilities. They modeled each of the service facilities as a single-server $M / M / 1$ queuing facility, which receives a given company-specific price for each customer served. Liu et al. [19] constructed a Stackelberg game to analyze the price and lead-time decisions when a supplier acts as leader and determines the lead-time and a retailer acts as follower and determines the price in a decentralized supply chain. Dobson and Stavrulaki [20] analyzed a single-facility problem to find out how a monopolist firm, who sells a single product to time-sensitive customers, would set the capacity, locate its facilities, and determine the price of the product offered to maximize profits. Pangburn and Stavrulaki [21] analyzed price and capacity levels to maximize profit of a chain in a monopolist market and found that a hybrid strategy based on a prioritized queuing discipline which combines elements of segmentation and pooling can outperform both the pure segmentation and pooling strategies. Zhao [22] assumed that retailers face stochastic demand competition on both price and inventory and focused on how a supplier should set contract in a supply chain system with these retailers. Pekgun et al. [23] examined a supply chain that serves price- and time-sensitive customers. In their model, decisions of price and delivery time were made by marketing and production department, respectively. Fathian et al. [24] presented an algorithm to determine an optimal price in internet based service providers for nondigital products that are sold via web sites. Ata and Mieghem [25] studied the effect of dynamic resource substitution in service systems on capacity requirements and responsiveness. They investigated whether two separate markets should be served by separate resources or by an integrated network where two markets dynamically share their resource. Anderson and Bao [26] investigated price competition with a linear demand function and compared two scenarios: in the first scenario, the supply chain is centralized and each distribution channel is vertically integrated, while in the second scenario, each element acts independently. Sinha et al. [27] modeled a priority queuing system for the optimal use of excess capacity of a resource which is shared by two classes of customers consisted of primary (existing) customers and secondary (new) customers. Jayaswal et al. [28] analyzed a supply chain in a market with two kinds of customers. In their work, the firm serves two different products with different prices and delivery times. They could choose dedicated or shared capacity in operational level and substituted products to achieve larger share of the market. Their aim was finding the best strategy for each production capacity and price to maximize whole profit of the chain. Teimoury et al. [29] investigated price, delivery time, and capacity decisions in an $M / M / 1$ make-to-order/service system with segmented market. Xiao and Qi [30] studied the equilibrium decisions in a two-stage supply chain with an all-unit quantity discount contract where the downstream manufacturer's demand is sensitive to three factors: the announced delivery lead-time, the delivery reliability, and the selling price of the product. They considered four different scenarios and found that an all-unit quantity discount scheme is preferable for the supply chain in most cases. Also, some applications and methods for selecting best strategy of pricing and delivery time decision making are surveyed in $[31,32]$.

There are some differences in our research in comparison with previous studies including applying evolutionary game approaches to find optimum strategy of chains for internal competition or coordination and simultaneously to find best policy of chains for external decisions such as price and delivery time. In addition, analyzing monopoly and duopoly markets in order to find the best strategy and policy in contrast of an electronic and a traditional supply chain is another contribution of our work.

The outline of the paper is as follows. In Section 2, the game strategy order and assumptions are introduced. In Section 3 we formulate the problems and competition scenarios. In Section 4, solution methods are developed for each scenario, and outcomes of the four cases are analyzed. 
Numerical examples are provided in Section 5. In Section 6 results of numerical example are discussed, and finally, Section 7 concludes the paper.

\section{Game Strategy Order}

In this section, a flowchart for game strategy order is developed to illustrate the steps of decision making in two competing supply chains and their manner of competition. There are two general policies for each supply chain: intercollaboration or intercompetition; based on these policies, we have four combined strategies in interaction of two chains. We formulate each strategy and find their corresponding solution method in what follows where the details are investigated.

2.1. The Flowchart of the Game Strategy Order. As can be seen in Figure 1, in the beginning there is a supply chain that serves in a monopoly market and acts traditionally. Then second chain enters the market and the market changes to duopoly where two chains start to compete to obtain a greater market share. Competition continues until equilibrium is established and all states are stable.

There are four combined strategies in this competition: if a supply chain chooses a centralized strategy, we can see intercollaboration behavior in the supply chain, but when a decentralized policy is applied, intercompetition behavior in the supply chain is observed. These four combined strategies may be displayed: (1) $\mathrm{TSC}_{C}-\mathrm{ESC}_{C}$; (2) $\mathrm{TSC}_{C}-\mathrm{ESC}_{\mathrm{Dec}}$; (3) TSC $_{\text {Dec }}-$ ESC $_{C}$; (4) TSC $_{\text {Dec }}-$ ESC $_{\text {Dec }}$. Whereas TSC $_{i}$ demonstrates $i$ th strategy of first chain, $\mathrm{ESC}_{j}$ demonstrates $j$ th strategy of second chain.

2.2. Assumptions. The assumptions of this research are categorized into two groups: (1) specific assumptions and (2) general assumptions. The specific assumptions are those made in this paper and the general ones are those mentioned in the literature of this study. The assumptions made regarding our research and related to our contribution are the following:

(i) Two supply chains each with two elements are considered. The elements in each supply chain are a manufacturer and a distributor. We suppose that each chain may choose either centralized or decentralized strategy. In centralized strategy, the elements of the chain cooperate, while in decentralized strategy there is competition between them. To the best of the authors' knowledge, no studies could be found on two rival chains with simultaneous competition or coordination between them and their internal elements.

(ii) Since the emergence of the electronic commerce, the nature of products and processes in companies has been changing from traditional to electronic. Since then, there have been challenges and interactions between electronic and traditional supply chains. To the best of the authors' knowledge, this paper is the first study to pay attention to these interactions. We assume that the first chain (TSC) acts in an isolated

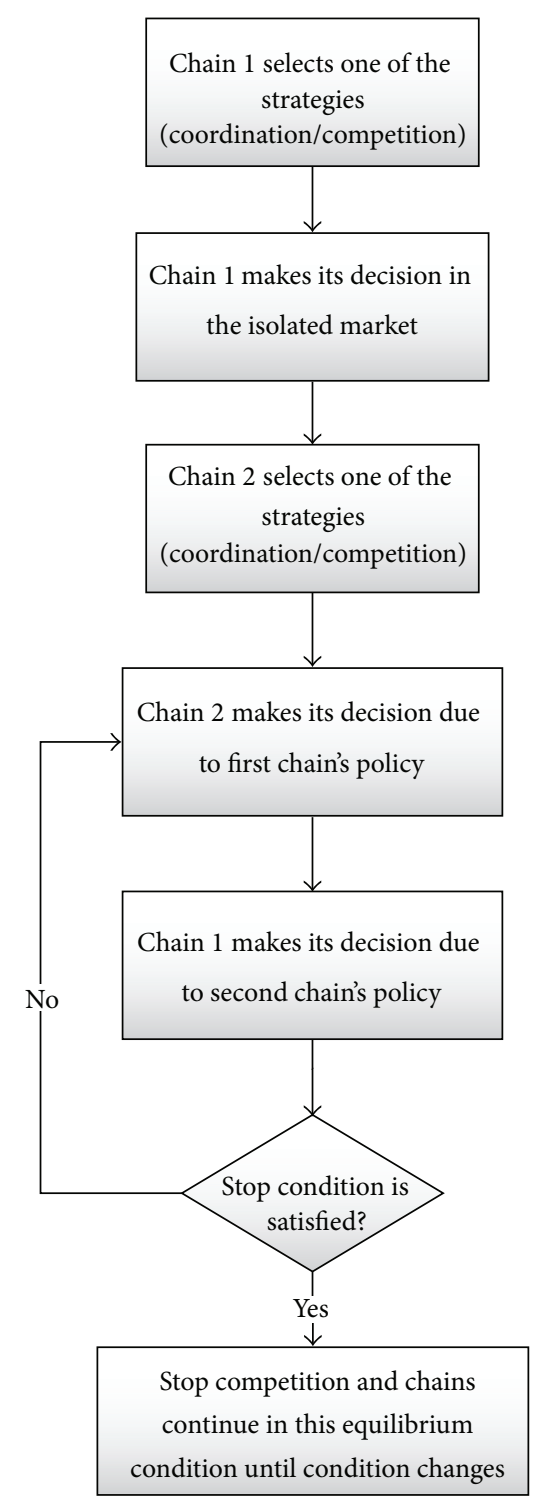

FIGURE 1: Flowchart of the game strategy order.

market as monopoly prior to competition, and all conditions are stable when the second chain (ESC) enters the market as an electronic supply chain and affects the stability of the market changing the proposed price and delivery time. The chains compete until equilibrium is established in the market.

(iii) In our study, the first chain (TSC) acts traditionally (i.e., not electronically) and the second one (ESC) acts electronically. The processes of each chain are different, and also the infrastructural costs and operational costs of each supply chain are different. To the best of our knowledge, such assumption is not considered in previous studies.

(iv) The processes of TSC and ESC are traditional and electronic respectively; therefore the infrastructural cost of TSC is lower than that of ESC, and the operational cost of TSC for producing and delivering 
products is higher than that of ESC. This supposition distinguishes ESC from TSC and transforms the quantitative differences to qualitative parameters.

General assumptions that are common in most of the previous studies are as follows.

(i) In the centralized chain, there is one price and one delivery time guarantee which is proposed by the chain to customers, while in decentralized chain, there is a price proposed by manufacturer to distributor, there is a price proposed by distributor to customers, and there is one delivery time which is proposed by manufacturer to customers. This is one of the most important contrasts between centralization and decentralization in supply chain management strategies.

(ii) Market is sensitive to price and delivery time for both chains. In previous works, some researchers concentrated on only one parameter $[26,33]$ while others aggregated price and delivery time into one parameter called the full price. Loch [34], Lederer and Li [6], Cachon and Harker [35], Armony and Haviv [36], and Chen and Wan [37] were the researchers who modeled customers' sensitivity to full price instead of price and delivery time independently.

(iii) In this paper we supposed that the customers' demand requests arrive according to a Poisson distribution with a rate of $\lambda$ that depends not only on its own price and delivery time guarantee but also on price and delivery time of the other chain. Poisson distribution is used by most of the previous studies; however, some of them assumed an unknown distribution for market demand or service rate. This leads to different queuing model such as $M / G / 1, G / M / 1$, and $G / G / 1$.

(iv) The service facilities in both centralized and decentralized supply chain are modeled as $M / M / 1$ queue. As previously mentioned, some researchers modeled their studies on other queuing model. Loch [34], Lederer and Li [6] applied $M / G / 1$ model in their studies.

(v) Customers are served based on FCFS priority discipline.

(vi) Without loss of generality, in this paper it is assumed that each customer receives services from only one chain at one moment, and the other chain only affects the market demands by proposing price and delivery time guarantee.

\section{Problem Formulation}

3.1. Sets and Indexes. Parameters, variables, and other notations used in formulation are as follows.

Index

$i$ : Number of chains; $i \in\{1,2\}$.

\section{Parameters}

$\beta_{p}$ : Sensitivity of customers' demand to price of its own supply chain; $\beta_{p} \geq 0$

$\beta_{L}$ : Sensitivity of customers' demand to delivery time guarantee of its own supply chain; $\beta_{L} \geq 0$

$\gamma_{p}$ : Sensitivity of customers' demand to price of competitor supply chain; $\gamma_{p} \geq 0$

$\gamma_{L}$ : Sensitivity of customers' demand to delivery time guarantee of competitor supply chain; $\gamma_{L} \geq 0$

$a^{i}$ : Total demand of market for chain $i ; i \in\{1,2\}$

$m_{m}^{i}:$ Infrastructural cost of chain $i ; i \in\{1,2\}$

$m_{d}^{i}$ : Advertising cost of chain $i ; i \in\{1,2\}$

$A^{i}$ : Operational cost of chain $i ; i \in\{1,2\}$

$\phi^{i}$ : Coordination cost between manufacturer and distributor in chain $i ; i \in\{1,2\}$

$\alpha^{i}$ : Service level of chain $i ; i \in\{1,2\}$

$W^{i}$ : Total expected time spent in chain $i$ in steady state; $i \in\{1,2\}$,

where own supply chain is considered as the chain from which the customer receives services while the competitor chain is the other one that tries to absorb these customers by proposing cost and delivery time.

\section{Variables}

$P_{m}^{i}$ : Price of chain $i$ proposed by manufacturer to distributor (in decentralized chain); $i \in\{1,2\}$

$P_{d}^{i}$ : Price of chain $i$ proposed by distributor to customer (in decentralized chain); $i \in\{1,2\}$

$P^{i}$ : Price of chain $i$ proposed by distributor to customers (in centralized chain); $i \in\{1,2\}$

$L^{i}$ : Delivery time of chain $i$ proposed to customers; $i \in\{1,2\}$.

\section{Profit Functions}

$\Pi_{\text {Mnf: }}^{i}$ Profit amount of manufacturer in chain $i$ (in decentralized chain); $i \in\{1,2\}$

$\Pi_{\mathrm{Dst}}^{i}:$ Profit amount of distributor in chain $i$ (in decentralized chain); $i \in\{1,2\}$

$\Pi^{i}$ : Total profit of chain $i$ (in centralized or decentralized chain); $i \in\{1,2\}$.

Both chains provide one product with identical features for a single type of customers; therefore, the utility of each product for customers is determined by price and delivery time proposed by each chain. Demand rate of chain $i$ can be written as

$$
\lambda^{i}=a^{i}-\beta_{p} P^{i}+\gamma_{p}\left(P^{j}-P^{i}\right)-\beta_{L} L^{i}+\gamma_{L}\left(L^{j}-L^{i}\right),
$$




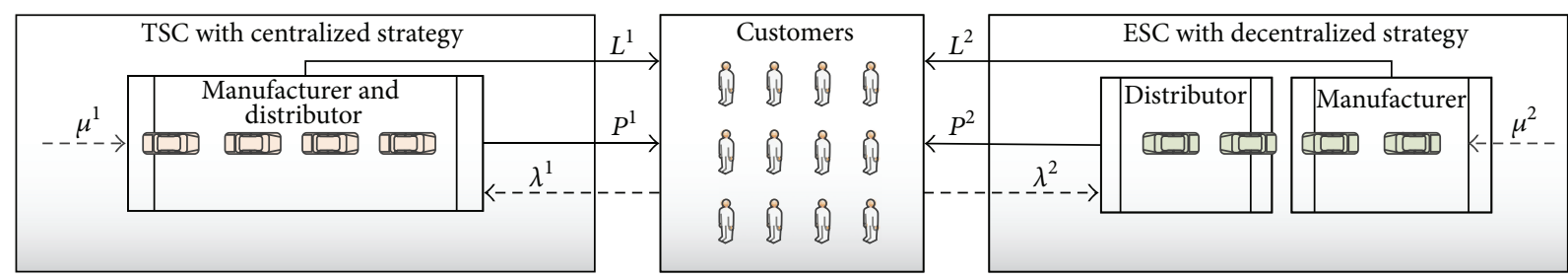

FIGURE 2: Competition between TSC with centralized strategy and ESC with decentralized strategy.

To formulate the problem, all aspects of competition are considered, and the combined policies of two chains are illustrated in what follows.

3.2. Competition Scenarios. In a centralized supply chain, there is coordination between internal elements of the chain and all elements of the chain compete with the other chain as one entity. In decentralized supply chain, in addition to competition between two chains there is an intercompetition between manufacturer (Mnf) and distributor (Dst). As mentioned earlier, there are four combined strategies for competition between the TSC and ESC. We explain and model those four combined strategies and relations of elements. In Figure 2 we can see a competition between TSC and ESC as a sample illustration. As we can see in this figure TSC chooses centralized policy and ESC uses decentralized policy.

TSC $_{C}$ versus $E S C_{C}$ (traditional supply chain with centralized strategy versus electronic supply chain with centralized strategy). Consider

$$
\begin{array}{ll}
\max _{P^{1}, L^{1}} & \Pi^{1}=\left(P^{1}-m_{m}^{1}-m_{d}^{1}\right) \lambda^{1}-A^{1} \mu^{1}-\phi^{1} \\
\text { s.t. } & S^{1}\left(L^{1}\right)=P\left(W^{1} \leq L^{1}\right) \geq \alpha^{1} \\
& P^{1}, L^{1} \geq 0, \\
\max _{P^{2}, L^{2}} & \Pi^{2}=\left(P^{2}-m_{m}^{2}-m_{d}^{2}\right) \lambda^{2}-A^{2} \mu^{2}-\phi^{2} \\
\text { s.t. } & S^{2}\left(L^{2}\right)=P\left(W^{2} \leq L^{2}\right) \geq \alpha^{2} \\
& P^{2}, L^{2} \geq 0 .
\end{array}
$$

$T_{S C}$ versus $E S C_{\text {Dec }}$ (traditional supply chain with centralized strategy versus electronic supply chain with decentralized strategy). Consider

$$
\begin{array}{ll}
\max _{P^{1}, L^{1}} & \Pi^{1}=\left(P^{1}-m_{m}^{1}-m_{d}^{1}\right) \lambda^{1}-A^{1} \mu^{1}-\phi^{1} \\
\text { s.t. } & S^{1}\left(L^{1}\right)=P\left(W^{1} \leq L^{1}\right) \geq \alpha^{1} \\
& P^{1}, L^{1} \geq 0, \\
\max _{P_{m}^{2}, L^{2}} & \Pi_{\mathrm{Mnf}}^{2}=\left(P_{m}^{2}-m_{m}^{2}\right) \lambda^{2}-A^{2} \mu^{2} \\
\text { s.t. } & S^{2}\left(L^{2}\right)=P\left(W^{2} \leq L^{2}\right) \geq \alpha^{2} \\
& P_{m}^{2}, L^{2} \geq 0,
\end{array}
$$

$$
\begin{aligned}
\max _{P_{d}^{2}} & \Pi_{\mathrm{Dst}}^{2}=\left(P_{d}^{2}-P_{m}^{2}-m_{d}^{2}\right) \lambda^{2} \\
& P_{d}^{2}, P_{m}^{2} \geq 0 .
\end{aligned}
$$

$T_{S C} C_{D e c}$ versus $E S C_{C}$ (traditional supply chain with decentralized strategy versus electronic supply chain with centralized strategy). Consider

$$
\begin{array}{ll}
\max _{P_{m}^{1}, L^{1}} & \Pi_{\mathrm{Mnf}}^{1}=\left(P_{m}^{1}-m_{m}^{1}\right) \lambda^{1}-A^{1} \mu^{1} \\
\text { s.t. } & S^{1}\left(L^{1}\right)=P\left(W^{1} \leq L^{1}\right) \geq \alpha^{1} \\
& P_{m}^{1}, L^{1} \geq 0, \\
\max _{P_{d}^{1}} & \Pi_{\mathrm{Dst}}^{1}=\left(P_{d}^{1}-P_{m}^{1}-m_{d}^{1}\right) \lambda^{1} \\
& P_{d}^{1}, P_{m}^{1} \geq 0, \\
\max _{P^{2}, L^{2}} & \Pi^{2}=\left(P^{2}-m_{m}^{2}-m_{d}^{2}\right) \lambda^{2}-A^{2} \mu^{2}-\phi^{2} \\
\text { s.t. } & S^{2}\left(L^{2}\right)=P\left(W^{2} \leq L^{2}\right) \geq \alpha^{2} \\
& P^{2}, L^{2} \geq 0 .
\end{array}
$$

$T_{S C} C_{\text {Dec }}$ versus $E S C_{\text {Dec }}$ (traditional supply chain with decentralized strategy versus electronic supply chain with decentralized strategy). Consider

$$
\begin{array}{ll}
\max _{P_{m}^{1}, L^{1}} & \Pi_{\mathrm{Mnf}}^{1}=\left(P_{m}^{1}-m_{m}^{1}\right) \lambda^{1}-A^{1} \mu^{1} \\
\text { s.t. } & S^{1}\left(L^{1}\right)=P\left(W^{1} \leq L^{1}\right) \geq \alpha^{1} \\
& P_{m}^{1}, L^{1} \geq 0, \\
\max _{P_{d}^{1}} & \Pi_{\mathrm{Dst}}^{1}=\left(P_{d}^{1}-P_{m}^{1}-m_{d}^{1}\right) \lambda^{1} \\
& P_{d}^{1}, P_{m}^{1} \geq 0, \\
\max _{P_{m}^{2}, L^{2}} & \Pi_{\mathrm{Mnf}}^{2}=\left(P_{m}^{2}-m_{m}^{2}\right) \lambda^{2}-A^{2} \mu^{2} \\
\text { s.t. } & S^{2}\left(L^{2}\right)=P\left(W^{2} \leq L^{2}\right) \geq \alpha^{2} \\
& P_{m}^{2}, L^{2} \geq 0, \\
\max _{P_{d}^{2}} & \Pi_{\mathrm{Dst}}^{2}=\left(P_{d}^{2}-P_{m}^{2}-m_{d}^{2}\right) \lambda^{2} \\
& P_{d}^{2}, P_{m}^{2} \geq 0 .
\end{array}
$$


TABLE 1: Best response amounts of $\mathrm{TSC}_{C}$ and $\mathrm{ESC}_{C}$.

\begin{tabular}{ll}
\hline TSC $_{C}$ & $\mathrm{ESC}_{C}$ \\
\hline$P^{1 *}=\frac{1}{2}\left\{\frac{a^{1}}{\beta_{P}+\gamma_{P}}+\frac{\gamma_{P} P^{2}+\gamma_{L} L^{2}}{\beta_{P}+\gamma_{P}}-\frac{\beta_{L}+\gamma_{L}}{\beta_{P}+\gamma_{P}} L^{1}+\left(m_{m}^{1}+m_{d}^{1}+A^{1}\right)\right\}$ & $P^{2 *}=\frac{1}{2}\left\{\frac{a^{2}}{\beta_{P}+\gamma_{P}}+\frac{\gamma_{P} P^{1}+\gamma_{L} L^{1}}{\beta_{P}+\gamma_{P}}-\frac{\beta_{L}+\gamma_{L}}{\beta_{P}+\gamma_{P}} L^{2}+\left(m_{m}^{2}+m_{d}^{2}+A^{2}\right)\right\}$ \\
\hline$\frac{A^{1} \ln (1-\alpha)}{\left(L^{1 *}\right)^{2}}+\frac{1}{2}\left(\beta_{L}+\gamma_{L}\right)$ & $\frac{A^{2} \ln (1-\alpha)}{\left(L^{2 *}\right)^{2}}+\frac{1}{2}\left(\beta_{L}+\gamma_{L}\right)$ \\
$\quad \times\left\{\frac{a^{1}}{\beta_{P}+\gamma_{P}}+\frac{\gamma_{P} P^{2}+\gamma_{L} L^{2}}{\beta_{P}+\gamma_{P}}-\frac{\beta_{L}+\gamma_{L}}{\beta_{P}+\gamma_{P}} L^{1 *}-\left(m_{m}^{1}+m_{d}^{1}+A^{1}\right)\right\}=0$ & $\times\left\{\frac{a^{2}}{\beta_{P}+\gamma_{P}}+\frac{\gamma_{P} P^{1}+\gamma_{L} L^{1}}{\beta_{P}+\gamma_{P}}-\frac{\beta_{L}+\gamma_{L}}{\beta_{P}+\gamma_{P}} L^{2 *}-\left(m_{m}^{2}+m_{d}^{2}+A^{2}\right)\right\}=0$ \\
\hline
\end{tabular}

As we can see, in centralized chain there is one objective function, but in decentralized chain there are two; this is because each element of the decentralized chain tries to optimize its benefit individually regardless of the other element.

We supposed that each customer is served by an $M / M / 1$ server, and the tail of the sojourn time distribution is known to be exponential. Therefore we have

$$
S^{i}\left(L^{i}\right)=P\left(W^{i} \leq L^{i}\right)=1-e^{\left(\lambda^{i}-\mu^{i}\right) L^{i}} \geq \alpha .
$$

\section{Solution Method}

According to the flowchart of the game strategy order, there are two general steps to solve the problem. The first step is related to solving the traditional supply chain's model in monopoly environment for finding the best strategy of TSC based on the price and delivery time. And second step is related to solving the traditional and electronic supply chain model in duopoly environment for finding the combined strategy of TSC and ESC according to price and delivery time.

Inspired by the solution methods of Jayaswal et al. [28], we developed solution methods for four combined strategies. To find the best policy of TSC when competes with ESC, first we solve the TSC model in monopoly environment; then we solve the TSC-ESC model in duopoly environment.

Without loss of the generality of the problems we can assume that the profit function, $\Pi^{i}$, is decreasing in service rate, $\mu^{i}$. Therefore to maximize $\Pi^{i}$ we should minimize $\mu^{i}$ while guaranteeing the desired service level $\alpha^{i}$; that is, to maximize $\Pi^{i}$, constraint (6) must be binding, and therefore the service rates are given by $\mu^{i}=\lambda^{i}-\ln (1-\alpha) / L^{i}$. By applying the amount of $\mu^{i}$, we can rewrite the objective functions and solve the models as follows.

\subsection{TSC $_{C}$ versus $E S C_{C}$}

Proposition 1. For given $L^{1 *}$, the optimum price, $P^{1 *}$ for TSC $_{C}$ in isolated environment is given by

$$
P^{1 *}=\frac{1}{2}\left\{\frac{a^{1}}{\beta_{P}}-\frac{\beta_{L}}{\beta_{P}} L^{1}+\left(m_{m}^{1}+m_{d}^{1}+A^{1}\right)\right\}
$$

And the optimum guaranteed delivery time, $L^{1 *}$, is given by unit root of

$$
\begin{aligned}
& \frac{A^{1} \ln (1-\alpha)}{\left(L^{1 *}\right)^{2}}+\frac{1}{2}\left(\beta_{L}\right)\left\{\frac{a^{1}}{\beta_{P}}-\frac{\beta_{L}}{\beta_{P}} L^{1 *}-\left(m_{m}^{1}+m_{d}^{1}+A^{1}\right)\right\} \\
& \quad=0 .
\end{aligned}
$$

Proposition 2. The optimum price, $P^{i *}$, and the optimum delivery time, $L^{i *}$, for both $\mathrm{TSC}_{C}$ and $\mathrm{ESC}_{\mathrm{C}}$ in competitive environment when the optimum policy of competitor is determined are given as shown in Table 1.

4.2. $T S C_{C}$ versus $E S C_{D e c}$. In this scenario, similar to Proposition 1, for given $L^{1 *}$, the optimum price, $P^{1 *}$ for TSC $_{C}$ in isolated environment is given by $P^{1 *}=(1 / 2)\left\{\left(a^{i} / \beta_{P}\right)-\right.$ $\left.\left(\beta_{L} / \beta_{P}\right)+\left(m_{m}^{1}+m_{d}^{1}+A^{1}\right)\right\}$, and the optimum guaranteed delivery time, $L^{1 *}$, is given by unit root of $A^{1} \ln (1-\alpha) /\left(L^{1 *}\right)^{2}+$ $(1 / 2)\left(\beta_{L}\right)\left\{\left(a^{1} / \beta_{P}\right)-\left(\beta_{L} / \beta_{P}\right) L^{1 *}-\left(m_{m}^{1}+m_{d}^{1}+A^{1}\right)\right\}=0$.

Proposition 3. The optimum price, $P^{i *}$, and the optimum delivery time, $L^{i *}$, for both $\mathrm{TSC}_{C}$ and $\mathrm{ESC}_{\mathrm{Dec}}$ in competitive environment when the optimum policy of competitor is determined are given as shown in Table 2.

\section{3. $T_{S C} C_{D e c}$ versus $E_{S C}$}

Proposition 4. For given $L^{1 *}$ and $P_{m}^{1 *}$, the optimum price of distributor, $P_{d}^{1 *}$, for TSC $_{D e c}$ in isolated environment is given by

$$
P_{d}^{1 *}=\frac{1}{2}\left\{\frac{a^{1}}{\beta_{P}}-\frac{\beta_{L}}{\beta_{P}} L^{1}+P_{m}^{1}+m_{d}^{1}\right\} .
$$

And the optimum price of manufacturer, $P_{m}^{1 *}$, is given by (10), and the optimum guaranteed delivery time, $L^{1 *}$, can be obtained by unit root of (11) as follows:

$$
\begin{gathered}
P_{m}^{1 *}=\frac{1}{2}\left\{\frac{a^{1}}{\beta_{P}}-\frac{\beta_{L}}{\beta_{P}} L^{1 *}+\left(m_{m}^{1}-m_{d}^{1}+A^{1}\right)\right\}, \quad \text { (10) } \\
\frac{A^{1} \ln (1-\alpha)}{\left(L^{1 *}\right)^{2}}+\frac{1}{4}\left(\beta_{L}\right)\left\{\frac{a^{1}}{\beta_{P}}-\frac{\beta_{L}}{\beta_{P}} L^{1 *}-\left(m_{m}^{1}+m_{d}^{1}+A^{1}\right)\right\}=0 .
\end{gathered}
$$

Proposition 5. The optimum prices, $P^{2 *}, P_{m}^{1 *}$, and $P_{d}^{1 *}$ and the optimum delivery time, $L^{i *}$, for both $T S C_{D e c}$ and 
TABLE 2: Best response amounts of $\mathrm{TSC}_{C}$ and $\mathrm{ESC}_{\mathrm{Dec}}$.

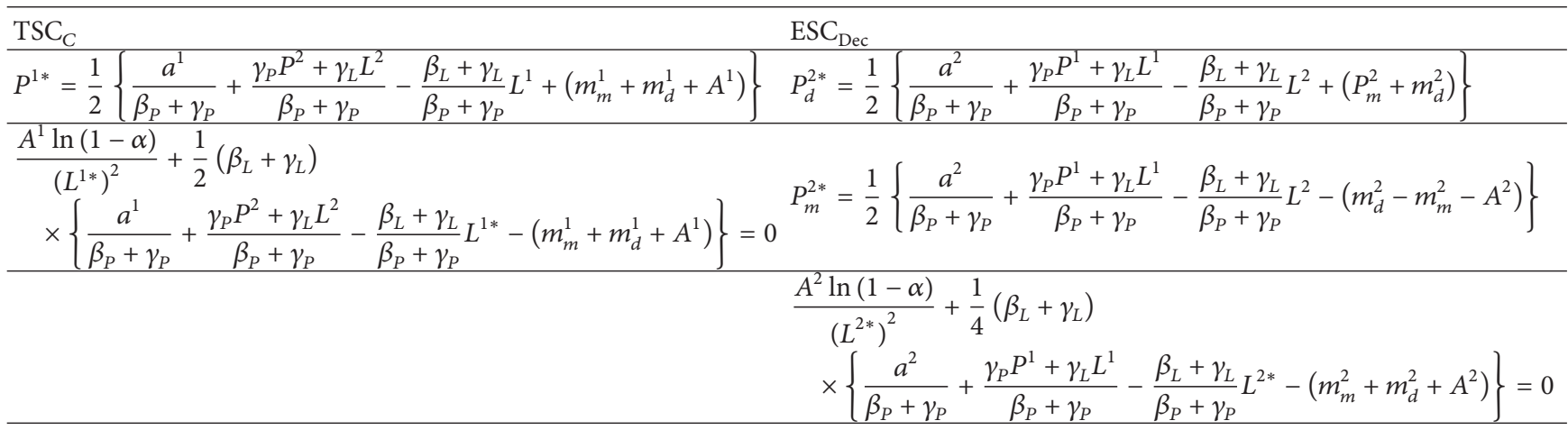

TABLE 3: Best response amounts of $\mathrm{TSC}_{\mathrm{Dec}}$ and $\mathrm{ESC}_{\mathrm{C}}$.

\begin{tabular}{ll}
\hline TSC $_{\text {Dec }}$ & ESC $_{C}$ \\
\hline$P_{d}^{1 *}=\frac{1}{2}\left\{\frac{a^{1}}{\beta_{P}+\gamma_{P}}+\frac{\gamma_{P} P^{2}+\gamma_{L} L^{2}}{\beta_{P}+\gamma_{P}}-\frac{\beta_{L}+\gamma_{L}}{\beta_{P}+\gamma_{P}} L^{1}+P_{m}^{1}+m_{d}^{1}\right\}$ & $P^{2 *}=\frac{1}{2}\left\{\frac{a^{2}}{\beta_{P}+\gamma_{P}}+\frac{\gamma_{P} P^{1}+\gamma_{L} L^{1}}{\beta_{P}+\gamma_{P}}-\frac{\beta_{L}+\gamma_{L}}{\beta_{P}+\gamma_{P}} L^{2}+\left(m_{m}^{2}+m_{d}^{2}+A^{2}\right)\right\}$ \\
\hline$P_{m}^{1 *}=\frac{1}{2}\left\{\frac{a^{1}}{\beta_{P}+\gamma_{P}}+\frac{\gamma_{P} P^{2}+\gamma_{L} L^{2}}{\beta_{P}+\gamma_{P}}-\frac{\beta_{L}+\gamma_{L}}{\beta_{P}+\gamma_{P}} L^{1}-\left(m_{d}^{1}-m_{m}^{1}-A^{1}\right)\right\}$ & $\frac{A^{2} \ln (1-\alpha)}{\left(L^{2 *}\right)^{2}}+\frac{1}{2}\left(\beta_{L}+\gamma_{L}\right)$ \\
$\frac{A^{1} \ln (1-\alpha)}{\left(L^{1 *}\right)^{2}}+\frac{1}{4}\left(\beta_{L}+\gamma_{L}\right)$ & $\times\left\{\frac{a^{2}}{\beta_{P}+\gamma_{P}}+\frac{\gamma_{P} P^{1}+\gamma_{L} L^{1}}{\beta_{P}+\gamma_{P}}-\frac{\beta_{L}+\gamma_{L}}{\beta_{P}+\gamma_{P}} L^{2 *}-\left(m_{m}^{2}+m_{d}^{2}+A^{2}\right)\right\}=0$ \\
$\quad \times\left\{\frac{a^{1}}{\beta_{P}+\gamma_{P}}+\frac{\gamma_{P} P^{2}+\gamma_{L} L^{2}}{\beta_{P}+\gamma_{P}}-\frac{\beta_{L}+\gamma_{L}}{\beta_{P}+\gamma_{P}} L^{1 *}-\left(m_{d}^{1}+m_{m}^{1}+A^{1}\right)\right\}=0$ & \\
\hline
\end{tabular}

TABLE 4: Best response amounts of $\mathrm{TSC}_{\mathrm{Dec}}$ and $\mathrm{ESC}_{\text {Dec }}$.

\begin{tabular}{ll}
\hline TSC $_{\text {Dec }}$ & ESC $_{\text {Dec }}$ \\
\hline$P_{d}^{1 *}=\frac{1}{2}\left\{\frac{a^{1}}{\beta_{P}+\gamma_{P}}+\frac{\gamma_{P} P_{d}^{2}+\gamma_{L} L^{2}}{\beta_{P}+\gamma_{P}}-\frac{\beta_{L}+\gamma_{L}}{\beta_{P}+\gamma_{P}} L^{1}+\left(P_{m}^{1}+m_{d}^{1}\right)\right\}$ & $P_{d}^{2 *}=\frac{1}{2}\left\{\frac{a^{2}}{\beta_{P}+\gamma_{P}}+\frac{\gamma_{P} P_{d}^{1}+\gamma_{L} L^{1}}{\beta_{P}+\gamma_{P}}-\frac{\beta_{L}+\gamma_{L}}{\beta_{P}+\gamma_{P}} L^{2}+\left(P_{m}^{2}+m_{d}^{2}\right)\right\}$ \\
\hline$P_{m}^{1 *}=\frac{1}{2}\left\{\frac{a^{1}}{\beta_{P}+\gamma_{P}}+\frac{\gamma_{P} P_{d}^{2}+\gamma_{L} L^{2}}{\beta_{P}+\gamma_{P}}-\frac{\beta_{L}+\gamma_{L}}{\beta_{P}+\gamma_{P}} L^{1}-\left(m_{d}^{1}-m_{m}^{1}-A^{1}\right)\right\}$ & $P_{m}^{2 *}=\frac{1}{2}\left\{\frac{a^{2}}{\beta_{P}+\gamma_{P}}+\frac{\gamma_{P} P_{d}^{1}+\gamma_{L} L^{1}}{\beta_{P}+\gamma_{P}}-\frac{\beta_{L}+\gamma_{L}}{\beta_{P}+\gamma_{P}} L^{2}-\left(m_{d}^{2}-m_{m}^{2}-A^{2}\right)\right\}$ \\
\hline$\frac{A^{1} \ln (1-\alpha)}{\left(L^{1 *}\right)^{2}}+\frac{1}{4}\left(\beta_{L}+\gamma_{L}\right)$ & $\frac{A^{2} \ln (1-\alpha)}{\left(L^{2 *}\right)^{2}}+\frac{1}{4}\left(\beta_{L}+\gamma_{L}\right)$ \\
$\quad \times\left\{\frac{a^{1}}{\beta_{P}+\gamma_{P}}+\frac{\gamma_{P} P_{d}^{2}+\gamma_{L} L^{2}}{\beta_{P}+\gamma_{P}}-\frac{\beta_{L}+\gamma_{L}}{\beta_{P}+\gamma_{P}} L^{1 *}-\left(m_{d}^{1}+m_{m}^{1}+A^{1}\right)\right\}=0$ & $\times\left\{\frac{a^{2}}{\beta_{P}+\gamma_{P}}+\frac{\gamma_{P} P_{d}^{1}+\gamma_{L} L^{1}}{\beta_{P}+\gamma_{P}}-\frac{\beta_{L}+\gamma_{L}}{\beta_{P}+\gamma_{P}} L^{2 *}-\left(m_{d}^{2}+m_{m}^{2}+A^{2}\right)\right\}=0$ \\
\hline
\end{tabular}

$E S C_{C}$ in competitive environment when the optimum policy of competitor is determined are given as shown in Table 3.

4.4. $T S C_{D e c}$ versus $E S C_{D e c}$. In this scenario, similar to Proposition 4 , the optimum price of distributor, $P_{d}^{1 *}$, the optimum price of manufacturer, $P_{m}^{1 *}$, and the optimum delivery time, $L^{1 *}$, for $\mathrm{TSC}_{\text {Dec }}$ in isolated environment are given by $P_{d}^{1 *}=(1 / 2)\left\{\left(a^{1} / \beta_{P}\right)-\left(\beta_{L} / \beta_{P}\right) L^{1}+P_{m}^{1}+m_{d}^{1}\right\}, P_{m}^{1 *}=$ $(1 / 2)\left\{\left(a^{1} / \beta_{P}\right)-\left(\beta_{L} / \beta_{P}\right) L^{1 *}+\left(m_{m}^{1}-m_{d}^{1}+A^{1}\right)\right\}, A^{1} \ln (1-$ $\alpha) /\left(L^{1 *}\right)^{2}+(1 / 4)\left(\beta_{L}\right)\left\{\left(a^{1} / \beta_{P}\right)-\left(\beta_{L} / \beta_{P}\right) L^{1 *}-\left(m_{m}^{1}+m_{d}^{1}+A^{1}\right)\right\}=$ 0 .

Proposition 6. The optimum prices, $P_{m}^{2 *}, P_{d}^{2 *}, P_{m}^{1 *}$, and $P_{d}^{1 *}$ and the optimum delivery time, $L^{i *}$, for both $T S C_{D e c}$ and
$E S C_{D e c}$ in competitive environment when the optimum policy of competitor is determined are given as shown in Table 4.

\section{Numerical Example}

We designed a numerical example to illustrate the comparison policies for each strategy of the TSC and ESC. The example is inspired by the numerical example which is provided by Jayaswal et al. [28] as shown in Table 5 .

As we can see, the infrastructural cost $\left(m_{m}\right)$ of ESC is more than TSC, because in the ESC more investment is needed, but the operational cost $(A)$ of ESC is lower than that of TSC, because the electronic processes of production is easier and cheaper than those of ESC. We formulated and solved each scenario by MATLAB 2008, and the results are presented in following sections. 
TABLE 5: Parameters of numerical example.

\begin{tabular}{|c|c|c|c|c|c|c|c|c|c|c|c|c|c|c|}
\hline$\beta_{P}$ & $\beta_{L}$ & $\gamma_{p}$ & $\gamma_{L}$ & $a^{1}$ & $a^{2}$ & $m_{m}^{1}$ & $m_{d}^{1}$ & $m_{m}^{2}$ & $m_{d}^{2}$ & $A^{1}$ & $A^{2}$ & $\alpha$ & $\phi^{1}$ & $\phi^{2}$ \\
\hline 0.5 & 0.9 & 0.4 & 0.4 & 10 & 10 & 2.9 & 0.1 & 3 & 0.1 & 2.2 & 1 & 0.99 & 0 & 0 \\
\hline
\end{tabular}
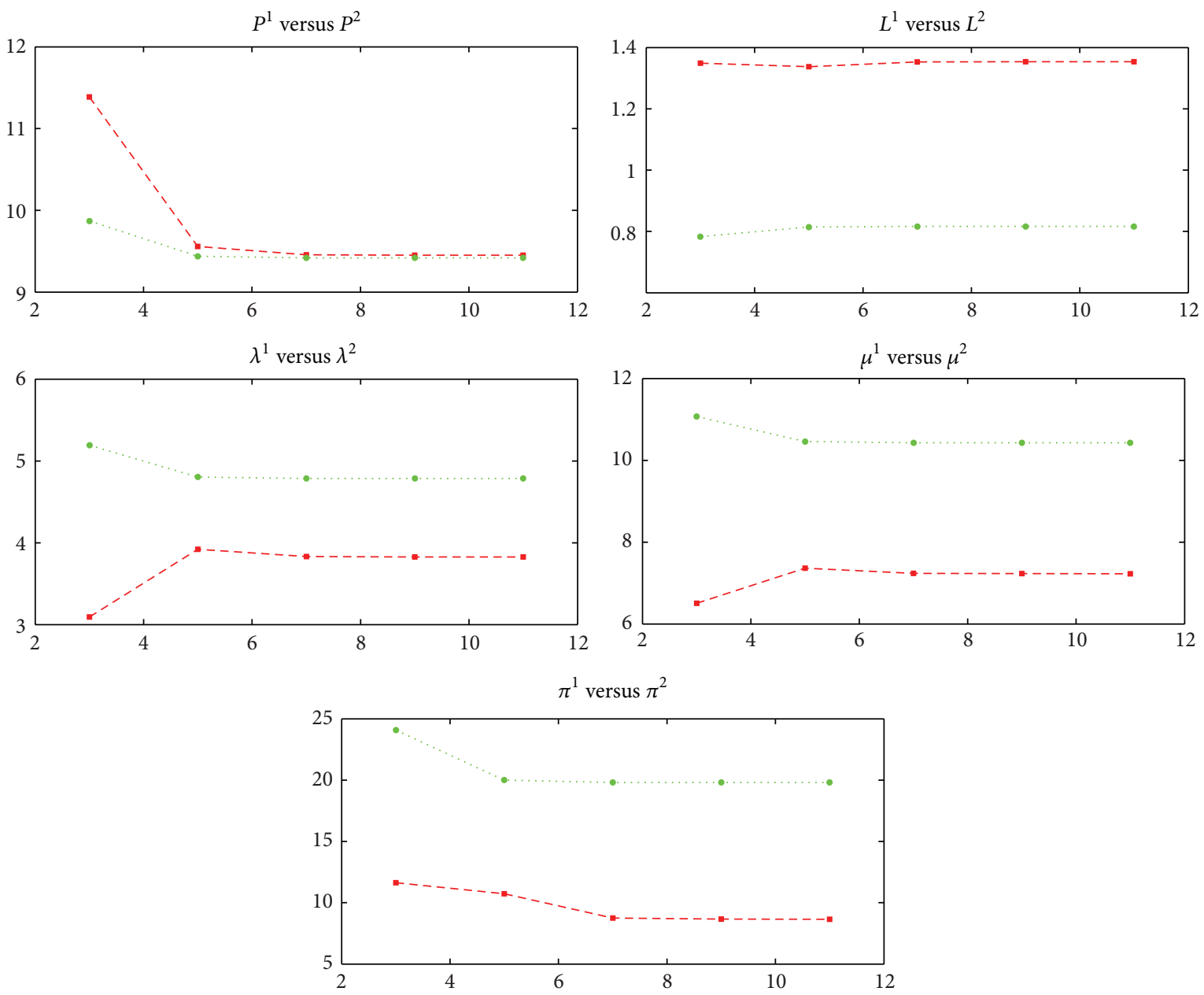

Figure 3: Results of competition between $\mathrm{TSC}_{C}$ and $\mathrm{ESC}_{C}$.

5.1. First Scenario: Competition between $T_{S C}$ and $E S C_{C}$. In this case, internal elements of each chain cooperate with each other, but the cost of coordination is zero. As mentioned before, in the beginning, the $\mathrm{TSC}_{C}$ achieves its best policy in monopoly market, by applying the developed models in Section 3.2 and solution method in Section 4.1; the best policy of $\operatorname{TSC}_{C}$ is $\left(P^{1 *}, L^{1 *}, \Pi^{1 *}\right)_{\operatorname{TSC}_{C}}:=(11.38,1.35,11.62)$. Then $\mathrm{ESC}_{C}$ enters the market and creates a duopoly market where two chains start to compete until steady state is established. The best policy of evolutionary competition of these two supply chains is illustrated as Figure 3 . The curves for TSC $_{C}$ and $\mathrm{ESC}_{C}$ are illustrated by red and green, respectively.

By ESC $_{C}$ entering the market, at first there is a large gap between price and delivery time of two chains. During the competition $\mathrm{TSC}_{C}$ reduces its cost, but the delivery time remains steady due to operational constraint. The demand rate, service rate, and profit of $\mathrm{ESC}_{C}$ are more than those of $\mathrm{TSC}_{C}$ in steady state; that is, $\left(P^{1 *}, L^{1 *}, \Pi^{1 *}\right)_{\mathrm{TSC}_{\mathrm{C}}} \quad:=(9.45,1.35,8.65)$ and $\left(P^{2 *}, L^{2 *}, \Pi^{2 *}\right)_{\operatorname{ESC}_{C}}:=(9.41,0.816,19.80)$.

5.2. Second Scenario: Competition between $T_{S C}$ and $E S C_{D e c}$. In this case, elements of TSC cooperate while the elements of ESC compete. In the beginning of the competition, $\mathrm{TSC}_{C}$ achieves its best policy in monopoly market by applying models developed in Section 3.2 and solution method in Section 4.2 ; the best policy of $\operatorname{TSC}_{C}$ is $\left(P^{1 *}, L^{1 *}, \Pi^{1 *}\right):=$ $(11.38,1.35,11.62)$. When $\mathrm{ESC}_{\mathrm{Dec}}$ enters the market, all conditions change to create a duopoly market where two chains start a competition until steady state is established. The best policy for the evolutionary competition of these two supply chains is illustrated in Figure 4 . The curves for TSC $_{C}$ and $\mathrm{ESC}_{\mathrm{Dec}}$ are displayed in red and green, respectively.

In this scenario, $\mathrm{ESC}_{\mathrm{Dec}}$ enters the market; however, it is unable to propose a competitive price in comparison with 

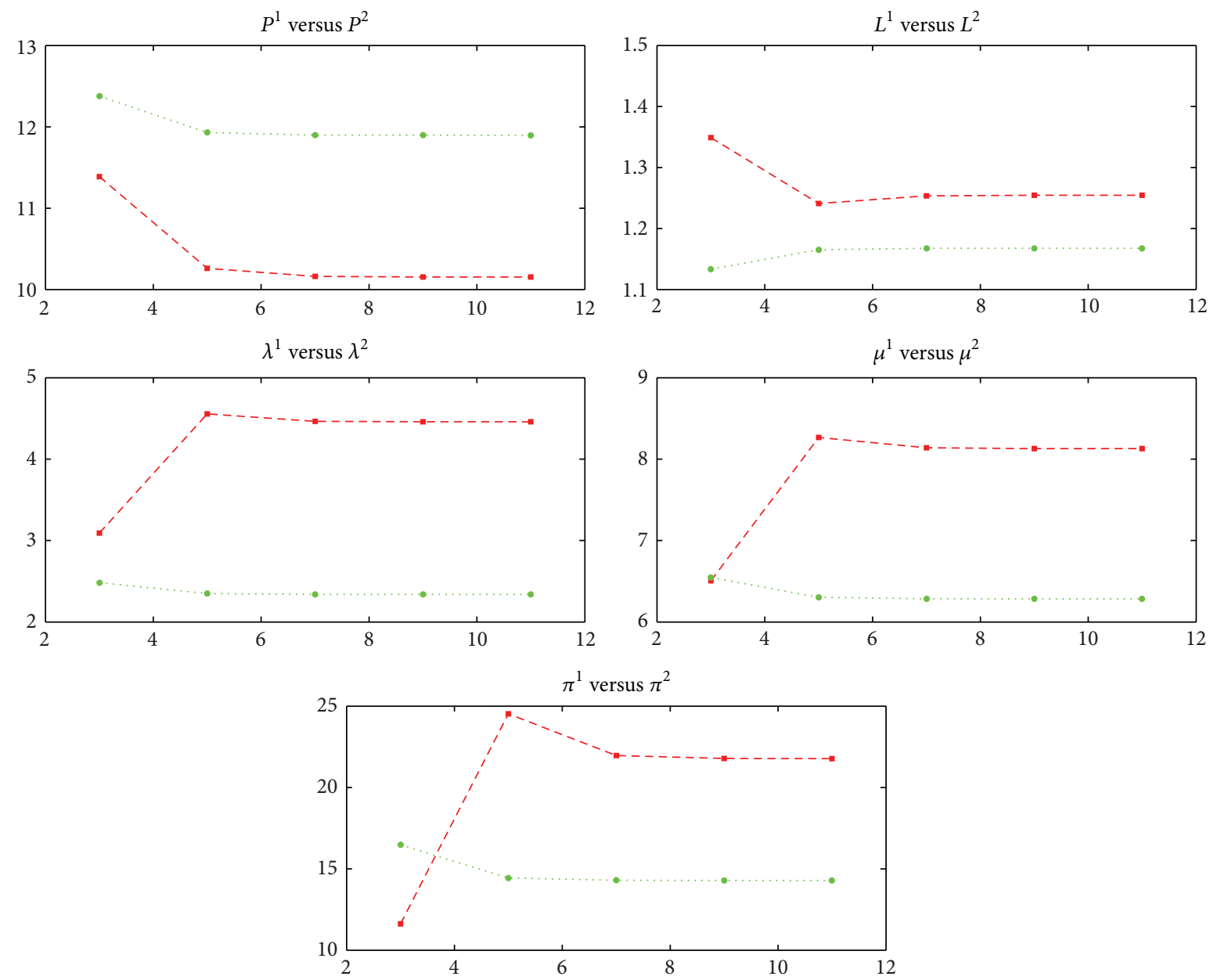

FIGURE 4: Results of competition between $\mathrm{TSC}_{C}$ and $\mathrm{ESC}_{\text {Dec }}$.

TSC $_{C}$ because $\mathrm{ESC}_{\text {Dec }}$ follows a decentralized strategy, and internal competition between its elements affects its proposed price to the customers. On the other hand, $\mathrm{ESC}_{\mathrm{Dec}}$ has faster services by applying electronic processes; therefore, its delivery time is lower than that of $\mathrm{TSC}_{C}$. In the beginning of the competition, the profit of $\mathrm{ESC}_{\mathrm{Dec}}$ is more than $\mathrm{TSC}_{C}$, but during the time $\mathrm{TSC}_{C}$ decreases its price and delivery time and obtains more market share. As we can see in the figure when steady state is established, delivery time, demand rate, service rate, and profit of $\mathrm{TSC}_{C}$ are more than those of $\mathrm{ESC}_{\mathrm{Dec}}:\left(P^{1 *}, L^{1 *}, \Pi^{1 *}\right)_{\mathrm{TSC}_{\mathrm{C}}}:=(10.15,1.25,21.77)$ and $\left(P_{d}^{2 *}, L^{2 *}, \Pi^{2 *}\right)_{\mathrm{ESC}_{\mathrm{C}}}:=(11.89,1.16,14.28)$.

5.3. Third Scenario: Competition between $T_{S C} C_{D e c}$ and $E S C_{C}$. In this case, elements of TSC compete while elements of ESC cooperate. In the beginning, $\mathrm{TSC}_{\mathrm{Dec}}$ achieves its best policy in monopoly market by applying the models developed in Section 3.2 and the solution method in Section 4.3, and the best policy of $\mathrm{TSC}_{\mathrm{Dec}}$ is $\left(P_{d}^{1 *}, P_{m}^{1 *}, L^{1 *}, \Pi^{1 *}\right):=$ $(10.69,13.59,2.00,6.69)$. When ESC $_{C}$ enters the market, all conditions change, and a duopoly market is created where the two chains compete until steady state is established. The best policy of the evolutionary competition between these two supply chains is illustrated in Figure 5 . The curves for TSC $_{\text {Dec }}$ and $\mathrm{ESC}_{C}$ are illustrated in red and green colors, respectively.

In this case, the $\mathrm{TSC}_{\mathrm{Dec}}$ does not have any competitive advantages because of its decentralized strategy (internal competition between its elements) and its traditional processes for delivering. In other words, the price and delivery time of $\mathrm{TSC}_{\mathrm{Dec}}$ are more than those of $\mathrm{ESC}_{C}$ when ESC $_{C}$ enters the market. During the competition, TSC $_{\text {Dec }}$ tries to reduce its price and delivery time, but there is a huge gap between the price and delivery time of these chains. Therefore, $\mathrm{ESC}_{\mathrm{C}}$ achieves a greater share of the market, and the demand rate, service rate, and profit of $\mathrm{ESC}_{C}$ are larger than those of $\mathrm{TSC}_{\mathrm{Dec}}$ in the steady state; that is, $\left(P_{d}^{1 *}, L^{1 *}, \Pi^{1 *}\right)_{\mathrm{TSC}_{C}}:=(11.12,1.92,11.92)$ and $\left(P^{2 *}, L^{2 *}, \Pi^{2 *}\right)_{\mathrm{ESC}_{C}}:=(9.94,0.77,24.81)$.

5.4. Fourth Scenario: Competition between $T_{S C} C_{D e c}$ and $E S C_{D e c}$. In this case, internal elements of TSC and ESC compete with each other. In the beginning, $\mathrm{TSC}_{\mathrm{Dec}}$ achieves its best policy in monopoly market by applying models developed in Section 3.2 and solution method in Section 4.4, 

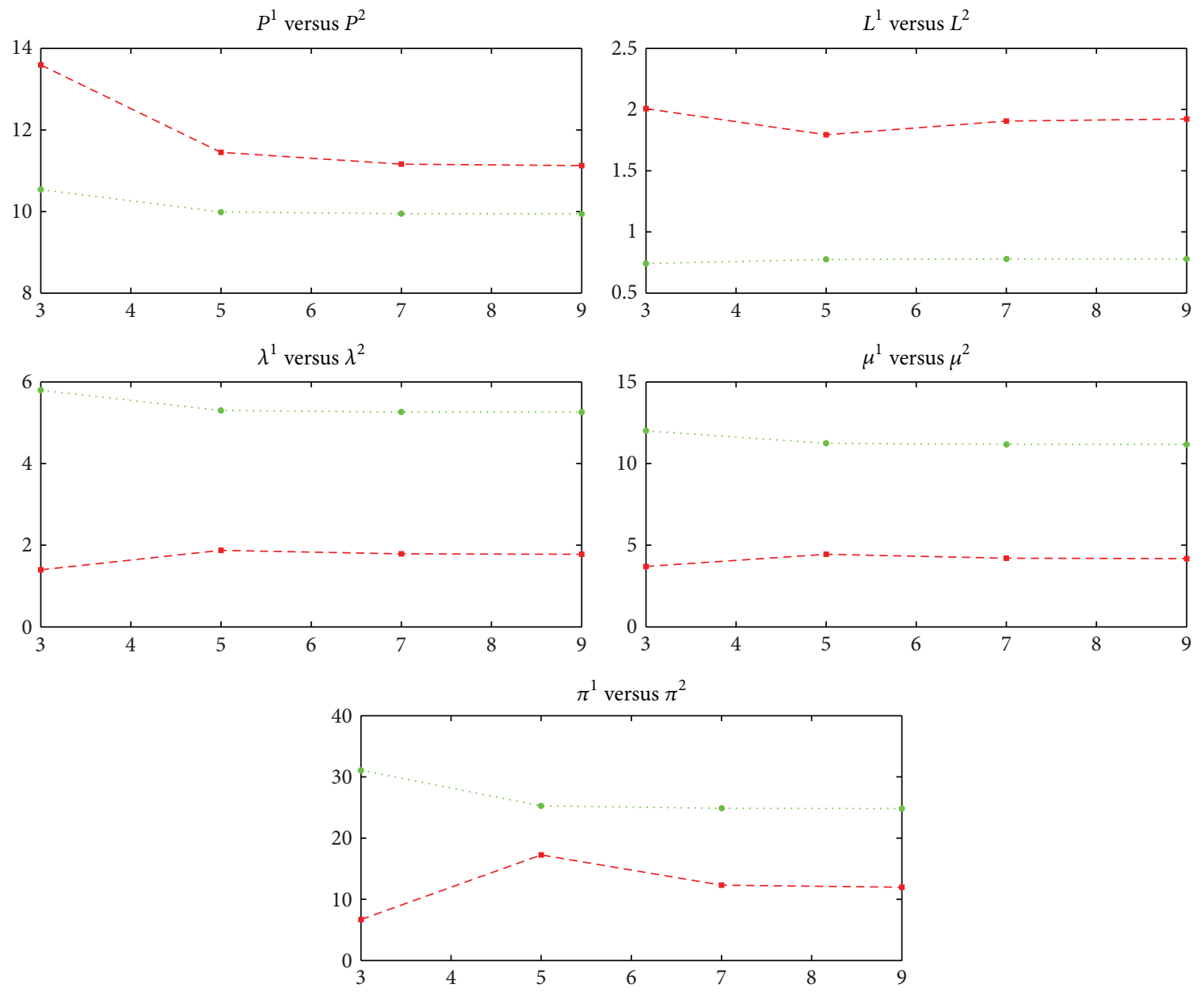

FIgURE 5: Results of competition between TSC $_{\text {Dec }}$ and $\mathrm{ESC}_{\mathrm{C}}$.

and the best policy of $\operatorname{TSC}_{\mathrm{Dec}}$ is $\left(P_{d}^{1 *}, P_{m}^{1 *}, L^{1 *}, \Pi^{1 *}\right):=$ $(10.69,13.59,2.00,6.69)$. When ESC $_{\text {Dec }}$ enters the market, all conditions change and a duopoly market is created in which two chains compete until steady state is reached. Figure 6 demonstrates the best policy of evolutionary competition between these two supply chains. $\mathrm{TSC}_{\mathrm{Dec}}$ and $\mathrm{ESC}_{\mathrm{Dec}}$ curves are colored in red and green, respectively.

In this scenario, the price of each chain is high because of their decentralized strategies. There is a close competition between two chains especially in price when $\mathrm{ESC}_{\mathrm{Dec}}$ enters the market; however, gradually, $\mathrm{TSC}_{\mathrm{Dec}}$ reduces its price, and therefore the difference between prices grows larger. Obviously, TSC $_{\text {Dec }}$ has no competitive advantages in delivery time, and there is an enormous gap between the delivery time of the two changes. In steady state, the demand rate, service rate, and profit of $\mathrm{ESC}_{\mathrm{Dec}}$ are more than those of $\mathrm{TSC}_{\text {Dec }}$; that is, $\left(P_{d}^{1 *}, L^{1 *}, \Pi^{1 *}\right)_{\mathrm{TSC}_{C}}:=(12.30,1.84,11.02)$ and $\left(P_{d}^{2 *}, L^{2 *}, \Pi^{2 *}\right)_{\mathrm{ESC}_{\mathrm{C}}}:=(12.89,1.10,18.94)$.

\section{Discussion}

The results of previous numerical examples are collected in Tables 6 and 7.
In this research, it is assumed that the cost of centralization is equal to zero; that is $\phi^{1}=\phi^{2}=0$. However, this is not the case in real-world situations, and the centralization cost causes a decrease in total profit of chains. The differences between profits of the chains in different scenarios are as shown in Table 7.

By analyzing the profit of chains, one can realize that if TSC chooses centralized strategy and decentralization cost is more than 7.49, then ESC can choose either of the strategies and obtain more profit in comparison with TSC. If TSC chooses decentralized strategy, for centralization cost of 12.89 and higher, the profit of TSC will be more than that of ESC if ESC chooses the decentralized strategy.

\section{Conclusion}

In this paper, the competition between two supply chains is investigated to find the optimal strategy for internal coordination or competition and the best policy of price and delivery time for external competition. The two supply chains, TSC and ESC, have traditional (nonelectronic) and electronic processes, respectively; therefore TSC has lower 

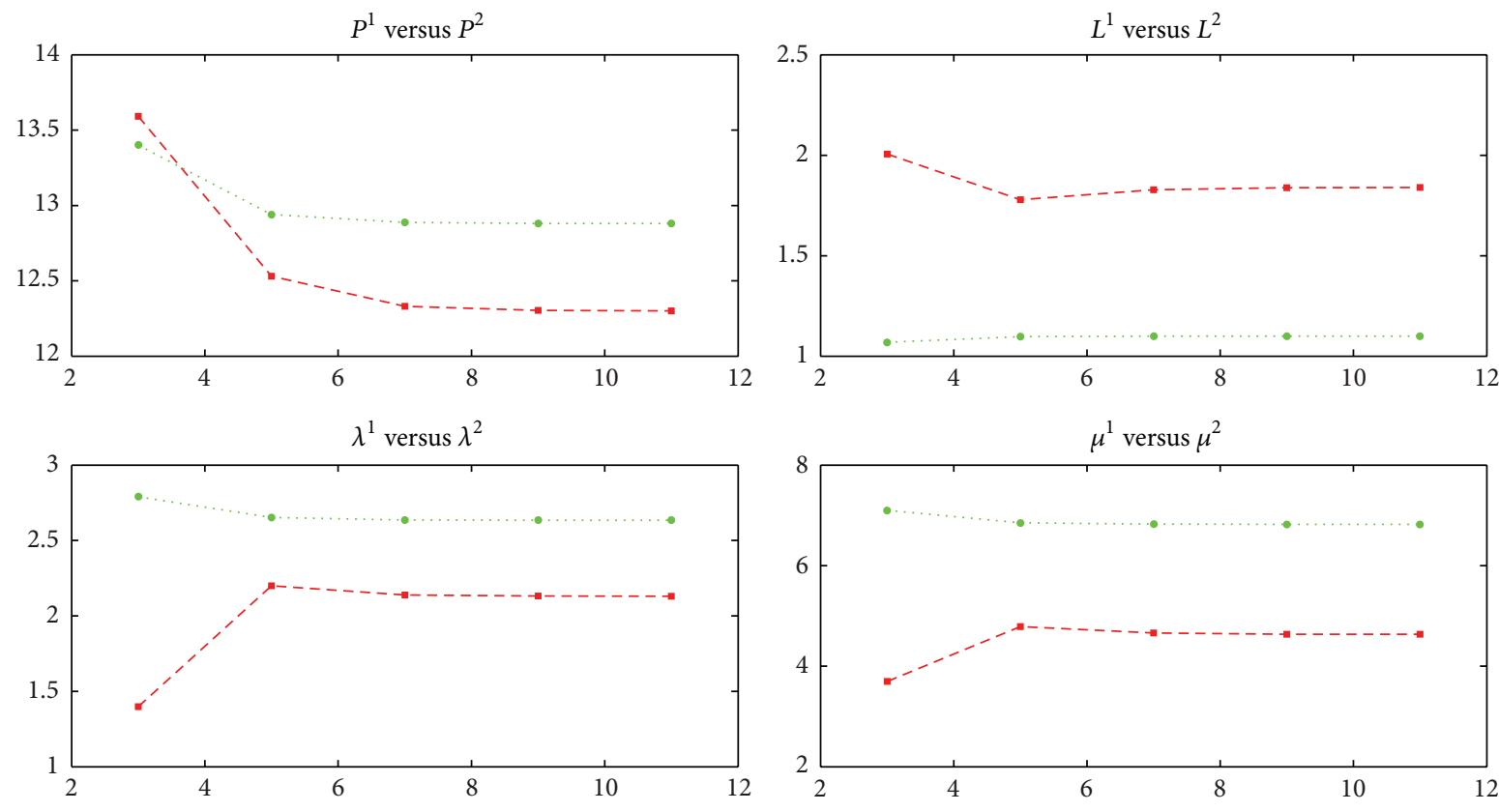

$\pi^{1}$ versus $\pi^{2}$

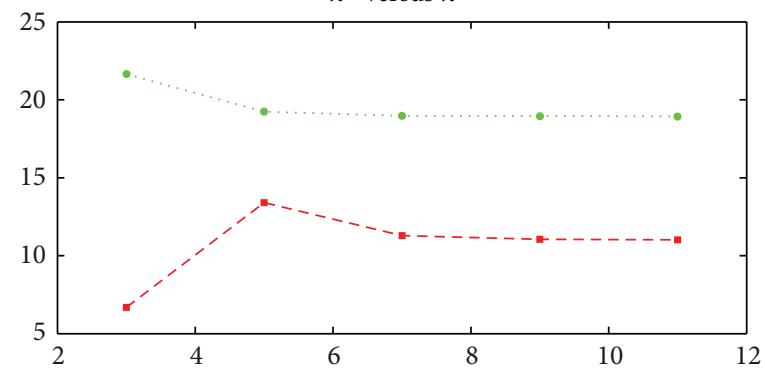

FIGURE 6: Results of competition between $\mathrm{TSC}_{\mathrm{Dec}}$ and $\mathrm{ESC}_{\mathrm{Dec}}$.

TABLE 6: Results of numerical example for each scenario of competition.

\begin{tabular}{lcr}
\hline TSC & Centralized strategy & ESC \\
\hline Centralized strategy & $\left(\Pi_{C}^{1 *}, \Pi_{C}^{2 *}\right)=(8.65,19.80)$ & $\left(\Pi_{C}^{1 *}, \Pi_{\text {Dec }}^{2 *}\right)=(21.77,14.28)$ \\
Decentralized strategy & $\left(\Pi_{\text {Dec }}^{1 *}, \Pi_{C}^{2 *}\right)=(11.92,24.81)$ & $\left(\Pi_{\text {Dec }}^{1 *}, \Pi_{\text {Dec }}^{2 *}\right)=(11.02,18.94)$ \\
\hline
\end{tabular}

TABLE 7: Differences between the profits of chains in each scenario of competition.

\begin{tabular}{lcc}
\hline TSC & Centralized strategy & ESC \\
\hline Centralized strategy & $\Pi_{C}^{2 *}-\Pi_{C}^{1 *}=11.15$ & $\Pi_{C}^{1 *}-\Pi_{\text {Dec }}^{2 *}=7.49$ \\
Decentralized strategy & $\Pi_{C}^{2 *}-\Pi_{\text {Dec }}^{1 *}=12.89$ & $\Pi_{\text {Dec }}^{2 *}-\Pi_{\text {Dec }}^{1 *}=7.92$ \\
\hline
\end{tabular}

infrastructural cost but higher operational cost in comparison with ESC. Our assumptions consist of market sensitivity to price and delivery time, in addition to supply chains services based on $M / M / 1$ queuing model.

An evolutionary game is developed, and all possible scenarios of competition between these two chains and their elements are studied. All scenarios are simulated for an illustrative numerical example and core competencies of each supply chain discussed based on its coordination strategy and market policy. We observed that supply chains preferences in internal strategy and external policy depend on centralization $\operatorname{cost}(\phi)$ and rival's strategy and policy as either a leader or follower in the market. Finally, it can be seen that usually the ESC has more opportunities to be victorious in comparison with TSC.

Considering two types of customers and assigning dedicated or shared capacity to them may be regarded as future research. In addition, assuming the centralization cost $\phi^{1}$ 
and $\phi^{2}$ in the case that internal elements of a chain are coordinating with each other is left for future research.

\section{References}

[1] H. Mendelson and S. Whang, "Optimal incentive-compatible priority pricing for the M/M/1 queue," Operations Research, vol. 38, no. 5, pp. 870-883, 1990.

[2] S. Dewan and H. Mendelson, "User delay costs and internal pricing for a service facility," Management Science, vol. 36, no. 12, pp. 1502-1517, 1990.

[3] S. Stidham Jr., "Pricing and capacity decisions for a service facility: stability and multiple local optima," Management Science, vol. 38, no. 8, pp. 1121-1139, 1992.

[4] W. J. Lee and D. Kim, "Optimal and heuristic decision strategies for integrated production and marketing planning," Decision Sciences, vol. 24, no. 6, pp. 1203-1214, 1993.

[5] L. Li and Y. S. Lee, "Pricing and delivery-time performance in a competitive environment," Management Science, vol. 40, no. 5, pp. 633-646, 1994.

[6] P. J. Lederer and L. Li, "Pricing, production, scheduling, and delivery-time competition," Operations Research, vol. 45, no. 3, pp. 407-420, 1997.

[7] K. Palaka, S. Erlebacher, and D. H. Kropp, "Lead-time setting, capacity utilization, and pricing decisions lead-time dependent demand," IIE Transactions, vol. 30, no. 2, pp. 151-163, 1998.

[8] K. C. So and J. S. Song, "Price, delivery time guarantees and capacity selection," European Journal of Operational Research, vol. 111, no. 1, pp. 28-49, 1998.

[9] A. A. Tsay and N. Agrawal, "Channel dynamics under price and service competition," Manufacturing and Service Operations Management, vol. 2, no. 4, pp. 372-391, 2000.

[10] K. C. So, "Price and time competition for service delivery," Manufacturing and Service Operations Management, vol. 2, no. 4, pp. 392-409, 2000.

[11] T. Boyaci and S. Ray, "Product differentiation and capacity cost interaction in time and price sensitive markets," Manufacturing and Service Operations Management, vol. 5, no. 1, pp. 18-36, 2003.

[12] S. Ray and E. M. Jewkes, "Customer lead time management when both demand and price are lead time sensitive," European Journal of Operational Research, vol. 153, no. 3, pp. 769-781, 2003.

[13] P. Afèche and H. Mendelson, "Pricing and priority auctions in queueing systems with a generalized delay cost structure," Management Science, vol. 50, no. 7, pp. 869-882, 2004.

[14] Y. Dai, X. Chao, S. Fang, and H. L. W. Nuttle, "Pricing in revenue management for multiple firms competing for customers," International Journal of Production Economics, vol. 98, no. 1, pp. 1-16, 2005.

[15] M. Leng and M. Parlar, "Game theoretic applications in supply chain management: a review," INFOR, vol. 43, no. 3, pp. 187-220, 2005.

[16] P. Pekgun, P. M. Griffin, and P. Keskinocak, "Centralized versus decentralized competition for price and lead-time sensitive demand," Management Science. In press.

[17] T. Boyaci and S. Ray, "The impact of capacity costs on product differentiation in delivery time, delivery reliability, and price," Production and Operations Management, vol. 15, no. 2, pp. 179197, 2006.
[18] G. Allon and A. Federgruen, "Competition in service industries," Operations Research, vol. 55, no. 1, pp. 37-55, 2007.

[19] L. Liu, M. Parlar, and S. X. Zhu, "Pricing and lead time decisions in decentralized supply chains," Management Science, vol. 53, no. 5, pp. 713-725, 2007.

[20] G. Dobson and E. Stavrulaki, "Simultaneous price, location, and capacity decisions on a line of time-sensitive customers," Naval Research Logistics, vol. 54, no. 1, pp. 1-10, 2007.

[21] M. S. Pangburn and E. Stavrulaki, "Capacity and price setting for dispersed, time-sensitive customer segments," European Journal of Operational Research, vol. 184, no. 3, pp. 1100-1121, 2008.

[22] X. Zhao, "Coordinating a supply chain system with retailers under both price and inventory competition," Production and Operations Management, vol. 17, no. 5, pp. 532-542, 2008.

[23] P. Pekgun, P. Griffin, and P. Keskinocak, "Coordination of marketing and production for price and leadtime decisions," IIE Transactions, vol. 40, no. 1, pp. 12-30, 2008.

[24] M. Fathian, S. J. Sadjadi, and S. Sajadi, "Optimal pricing model for electronic products," Computers and Industrial Engineering, vol. 56, no. 1, pp. 255-259, 2009.

[25] B. Ata and J. A. V. Mieghem, "The value of partial resource pooling: should a service network be integrated or productfocused?" Management Science, vol. 55, no. 1, pp. 115-131, 2009.

[26] E. J. Anderson and Y. Bao, "Price competition with integrated and decentralized supply chains," European Journal of Operational Research, vol. 200, no. 1, pp. 227-234, 2010.

[27] S. K. Sinha, N. Rangaraj, and N. Hemachandra, "Pricing surplus server capacity for mean waiting time sensitive customers," European Journal of Operational Research, vol. 205, no. 1, pp. 159-171, 2010.

[28] S. Jayaswal, E. Jewkes, and S. Ray, "Product differentiation and operations strategy in a capacitated environment," European Journal of Operational Research, vol. 210, no. 3, pp. 716-728, 2011.

[29] E. Teimoury, M. Modarres, A. K. Monfared, and M. Fathi, "Price, delivery time, and capacity decisions in an M/M/1 maketo-order/service system with segmented market," International Journal of Advanced Manufacturing Technology, vol. 57, no. 1-4, pp. 235-244, 2011.

[30] T. Xiao and X. Qi, "A two-stage supply chain with demand sensitive to price, delivery time, and reliability of delivery," Annals of Operations Research, 2012.

[31] S. Sinha and S. P. Sarmah, "Coordination and price competition in a duopoly common retailer supply chain," Computers and Industrial Engineering, vol. 59, no. 2, pp. 280-295, 2010.

[32] G. Hua, S. Wang, and T. C. E. Cheng, "Price and lead time decisions in dual-channel supply chains," European Journal of Operational Research, vol. 205, no. 1, pp. 113-126, 2010.

[33] E. Kalai, M. I. Kamien, and M. Rubinovitch, "Optimal service speeds in a competitive environment," Management Science, vol. 38, no. 8, pp. 1154-1163, 1992.

[34] C. Loch, Pricing in markets sensitive to delay [Ph.D. thesis], Stanford University, Stanford, Calif, USA, 1991.

[35] G. R. P. Cachon and P. T. Harker, "Competition and outsourcing with scale economies," Management Science, vol. 48, no. 10, pp. 1314-1333, 2002.

[36] M. Armony and M. Haviv, "Price and delay competition between two service providers," European Journal of Operational Research, vol. 147, no. 1, pp. 32-50, 2003.

[37] H. Chen and Y. W. Wan, "Price competition of make-to-order firms," IIE Transactions, vol. 35, no. 9, pp. 817-832, 2003. 


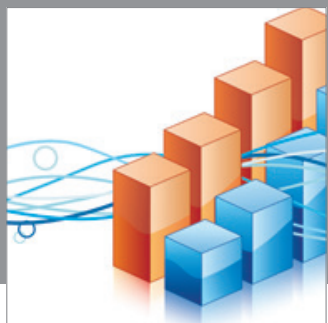

Advances in

Operations Research

mansans

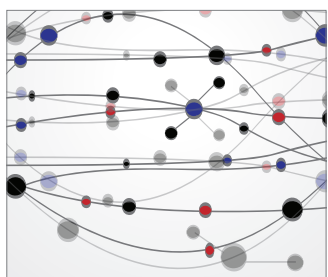

The Scientific World Journal
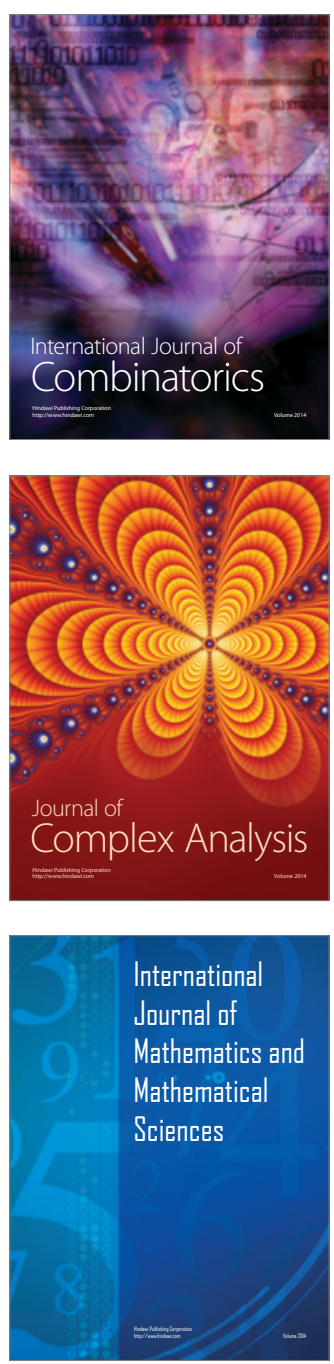
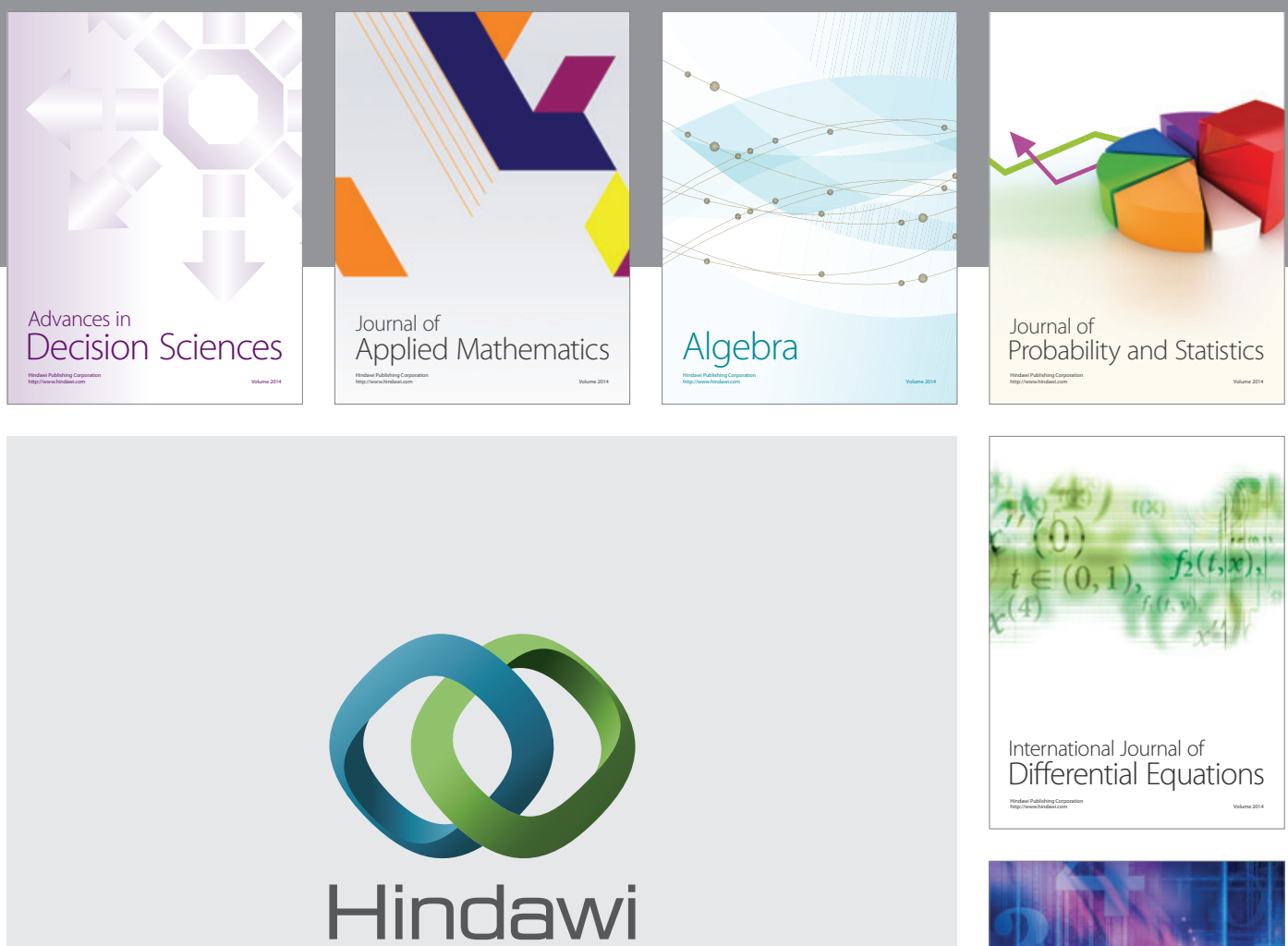

Submit your manuscripts at http://www.hindawi.com
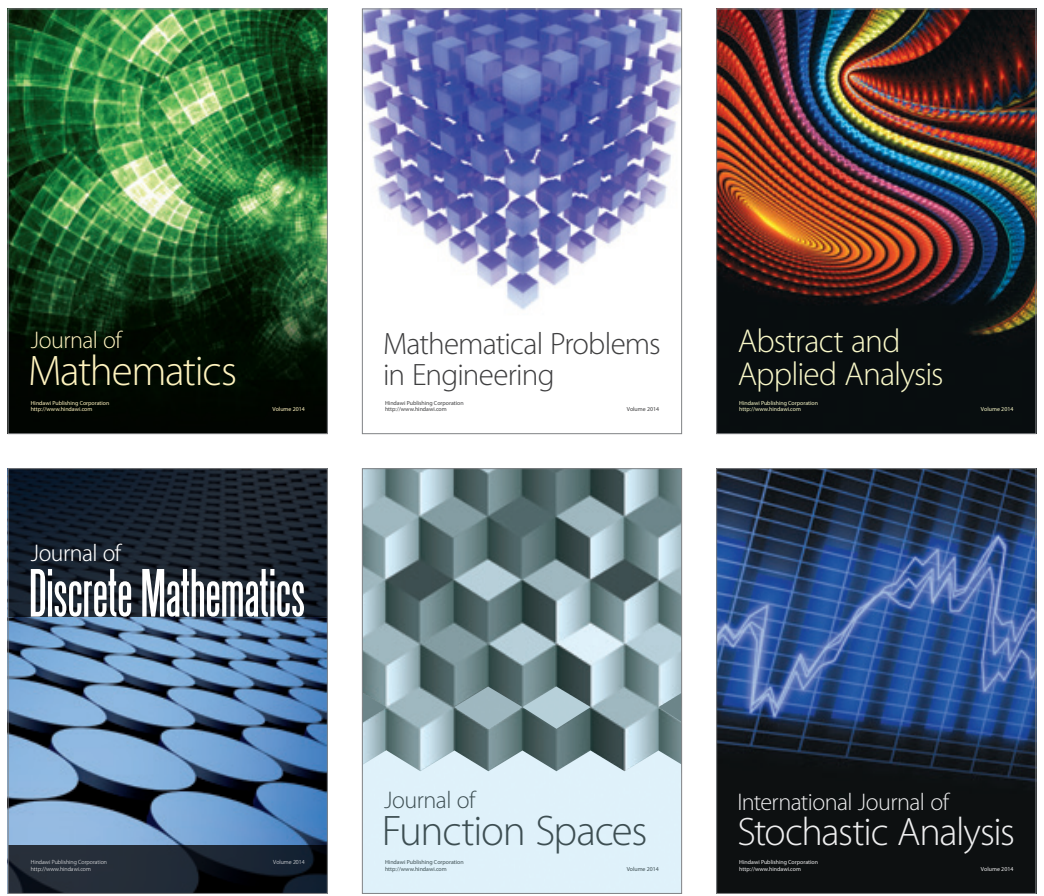

Journal of

Function Spaces

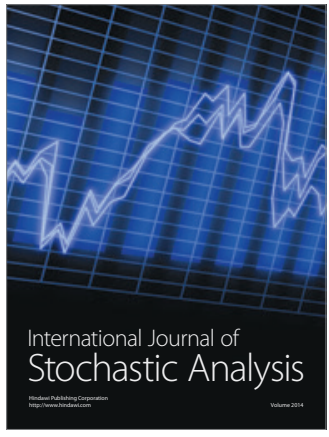

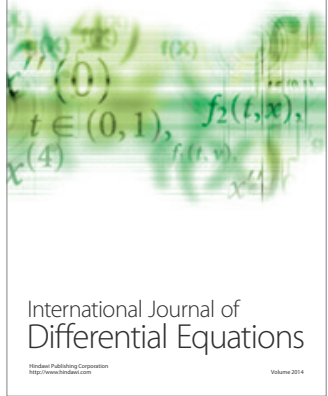
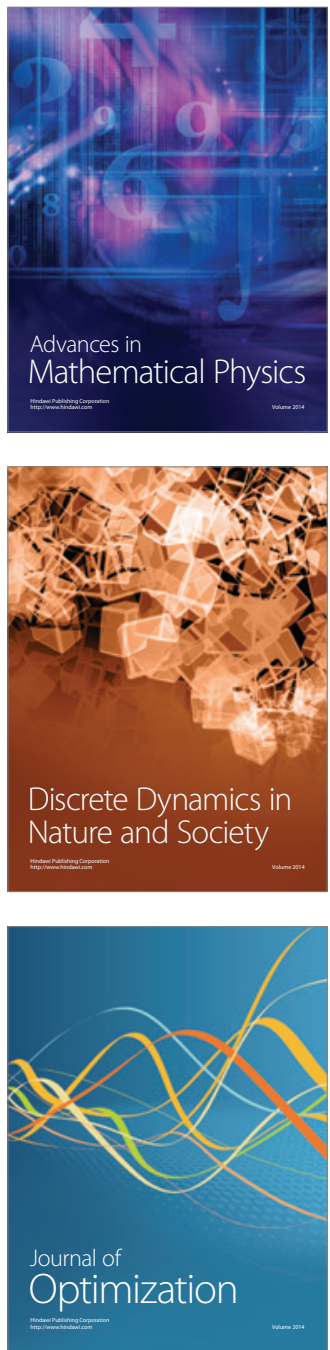